\title{
An in vitro model system to study gene therapy in the human inner ear
}

\author{
BW Kesser ${ }^{1}$, GT Hashisaki ${ }^{1}$, K Fletcher ${ }^{1}$, H Eppard $^{2}$ and JR Holt ${ }^{1,2}$ \\ ${ }^{1}$ Department of Otolaryngology - Head and Neck Surgery, University of Virginia School of Medicine, Charlottesville, VA, USA and \\ ${ }^{2}$ Department of Neuroscience, University of Virginia School of Medicine, Charlottesville, VA, USA
}

The confined fluid-filled labyrinth of the human inner ear presents an opportunity for introduction of gene therapy reagents designed to treat hearing and balance dysfunction. Here we present a novel model system derived from the sensory epithelia of human vestibular organs and show that the tissue can survive up to 5 days in vitro. We generated organotypic cultures from 26 human sensory epithelia excised at the time of labyrinthectomy for intractable Meniere's disease or vestibular schwannoma. We applied multiply deleted adenoviral vectors at titers between $10^{5}$ and $10^{8}$ viral particles $/ \mathrm{ml}$ directly to the cultures for 4-24 $\mathrm{h}$ and examined the tissue 12-96 $h$ post-transfection. We noted robust expression of the exogenous transgene, green fluorescent protein (GFP), in hair cells and supporting cells suggesting both were targets of adenoviral transfection. We also transfected cultures with a vector that carried the genes for GFP and KCNQ4, a potassium channel subunit that causes dominant-progressive hearing loss when mutated. We noted a positive correlation between GFP fluorescence and KCNQ4 immunolocalization. We conclude that our in vitro model system presents a novel and effective experimental paradigm for evaluation of gene therapy reagents designed to restore cellular function in patients who suffer from inner ear disorders.

Gene Therapy (2007) 14, 1121-1131; doi:10.1038/

sj.gt.3302980; published online 14 June 2007

Keywords: hair cell; auditory; vestibular; deafness; adenovirus; KCNQ4

\section{Introduction}

Dysfunction of the inner ear organs of hearing and balance affects more than 250 million people worldwide. The majority of these cases result from genetic and/or environmental damage to cells that reside within the inner ear sensory epithelia, including the primary sensory cells, known as hair cells. Despite the enormous socioeconomic impact of inner ear dysfunction, there are no pharmacologic or genetic therapies currently available.

The inner ear contains six sensory organs, five that subserve vestibular function and the cochlea which subserves auditory function. Each organ contains a sensory epithelium that consists of a monolayer of hair cells interdigitated with supporting cells. Both hair cells and supporting cells can be affected by mutations in some of the over sixty genes identified that cause deafness and balance disorders. ${ }^{1}$ Furthermore, loss of hair cells and the inability to regenerate them is the most common cause of acquired hearing loss. Possible treatment strategies include transfer of wild-type genes into either hair cells or supporting cells to restore gene function as well as introduction of factors that induce transdifferentiation of supporting cells into hair cells to

Correspondence: Dr JR Holt, Department of Neuroscience and Department of Otolaryngology, University of Virginia School of Medicine, Box 801392, Charlottesville, VA 22908, USA.

E-mail: jeffholt@virginia.edu

Received 12 December 2006; revised 16 April 2007; accepted 24 April 2007; published online 14 June 2007 restore sensory cell function. As such, both hair cells and supporting cells represent possible targets for gene therapeutic interventions designed to restore inner ear function.

To begin to address gene therapy approaches to treat inner ear dysfunction, we developed an in vitro preparation of human inner ear sensory epithelia. We found that the tissue remained viable for at least 5 days in vitro. We also present proof-of-principle evidence that adenovirus can transfect both human hair cells and, equally important, supporting cells and can drive expression of the wild-type form of human deafness genes, such as the potassium channel, KCNQ4. Therefore, we propose that our in vitro preparation of the human inner ear will be a valuable tool for screening the efficacy of pharmacologic and gene therapy reagents that target the cells of inner ear sensory epithelia. Furthermore, we place multiply deleted adenovirus as the first entry on the list of potential vectors that can be developed to target human inner ear cells in vivo.

\section{Results}

Viability of human explant cultures

We harvested 26 sensory epithelia from nine consented patients at the time of surgical intervention for intractable Meniere's disease or vestibular schwannoma. The tissue was transferred from the patient to a Petri dish that contained minimum essential medium (MEM) supplemented with $10 \mathrm{mM} N$-2-hydroxyethylpiperazine- 
$N^{\prime}$-2-ethanesulfonic acid (HEPES) buffer and $0.05 \mathrm{mg} / \mathrm{ml}$ ampicillin. Accessory structures were trimmed away so that just the sensory epithelium was retained. The tissue was mounted on a glass coverslip beneath two flexible glass fibers glued at one end with Sylgard (World Precision Instruments, Sarasota, FL, USA). The fibers were $50-100 \mu \mathrm{m}$ in diameter, $15 \mathrm{~mm}$ long and placed $\sim 1.2 \mathrm{~mm}$ apart (Figure 1a). The tension in the fibers was sufficient to hold the tissue in place for up to $120 \mathrm{~h}$, the longest time point we tested.

Immediately following tissue harvest and mounting, each sample was examined visually using differential interference contrast (DIC) microscopy at $\times 40$ and $\times 63$. In the otolith organs, the saccule and utricle, we often observed stray otoconia and remnants of the otolithic membrane, splayed stereocilia and occasionally intact hair bundles. For some samples, we fixed the tissue and
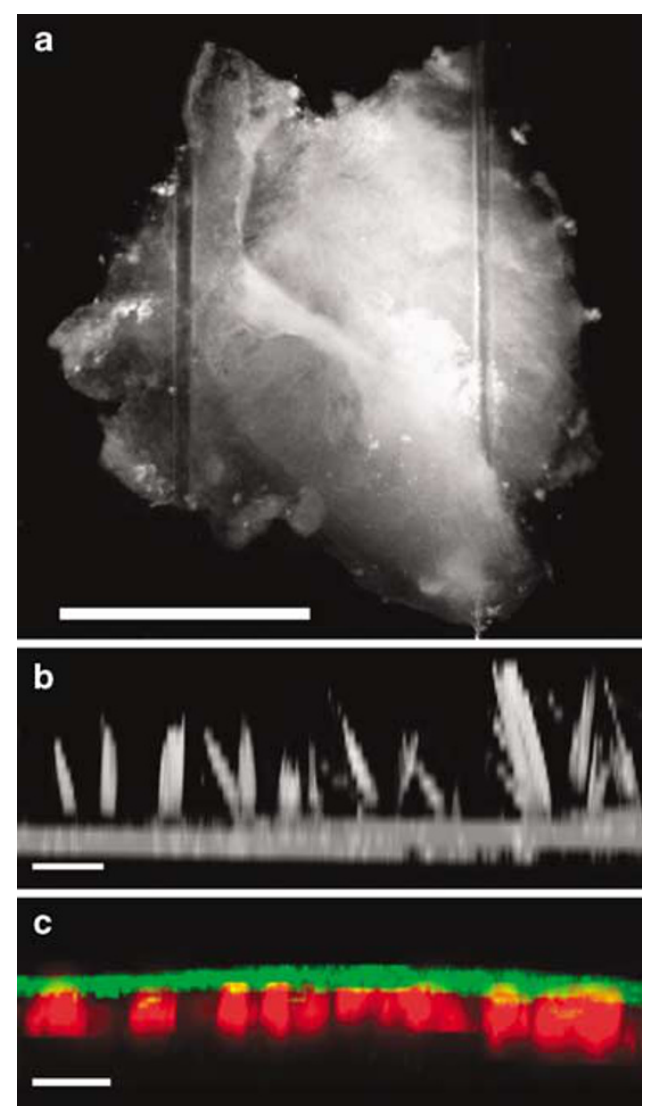

Figure 1 Images of the human vestibular sensory epithelium in vitro. (a) DIC image of a human utricle explant viewed from above the apical surface. The tissue was harvested from the patient and the accessory structures including the nonsensory epithelium, otolithic membrane and otoconia were removed. Just the sensory epithelium was retained and mounted on a glass coverslip, held in place by two glass fibers. Scale bar $=1 \mathrm{~mm}$. (b) After $48 \mathrm{~h}$ in culture, the tissue was fixed and stained with Alexa Fluor 546-conjugated phalloidin and viewed from above using confocal microscopy. The cross-sectional view was generated from a projection of a stack of 14 image planes, focused at $1.5 \mu \mathrm{m}$ intervals. Scale bar $=10 \mu \mathrm{m}$. Note the actin-rich hair bundles that protrude 12-20 $\mu \mathrm{m}$ above the apical surface. (c) The crista harvested from the posterior semicircular canal of patient \#9 was cultured for 5 days after which it was fixed, stained with Alexa Fluor 488-conjugated phalloidin (green) and myosin VIIa (red). The tissue was viewed from above and the crosssectional image was generated from a projection of a stack of 14 image planes. Scale bar $=20 \mu \mathrm{m}$. stained with Alexa Fluor 546 phalloidin to illuminate the hair bundles. Figure 1b shows a cross-sectional projection from a stack of confocal images taken at several focal planes after 2 days in culture. The image reveals numerous hair bundles from a human utricle with heights ranging from 12 to $20 \mu \mathrm{m}$. In the cristae of the semicircular canals, we never observed cupular membranes or hair bundles. It was not clear whether the lack of hair bundles in the cristae resulted from vestibular pathology or surgical excision of the tissue, yet we suspect the latter as cristae hair bundles are deeply embedded in the cupulae which were removed at the time of dissection. In the utricle and saccule, the presence of hair bundles was strong evidence suggesting the presence of hair cells. In samples that lacked visible hair bundles, we were able to confirm the presence of hair cells using the hair cell marker, myosin VIIa, which has been shown to specifically label hair cells in lower vertebrates. ${ }^{2}$ Figure 1c shows a confocal image of a crosssection of the crista harvested from the posterior semicircular canal. The tissue was placed in a conventional cell culture incubator, maintained at $37^{\circ} \mathrm{C},>50 \%$ relative humidity and $5 \% \mathrm{CO}_{2}$ for 5 days. It was then fixed, stained with Alexa Fluor 488 phalloidin (green) and counter stained for myosin VIIa (red) which revealed the presence of multiple cell bodies that had morphologies consistent with hair cells. Type I and type II hair cell morphologies were apparent in all samples, though subcellular features were often obscured due to the thickness of the tissue.

In a few tissue samples, we noted evidence of cellular decay as indicated by cell swelling and intracellular Brownian motion, in which case the tissue was not selected for further analysis. In the samples we choose to examine more closely, we occasionally noted some tissue scaring, as evidenced by phalloidin-labeled radial actin filaments in supporting cells. However, as it was present it both the cultured epithelia and the acutely excised tissue, we suspect that it may have resulted either from the prior history of the patient or the trauma of the surgical excision, but cannot exclude the possibility that the scaring in the cultured epithelia resulted from suboptimal culture conditions.

\section{Transfection of human sensory epithelia}

To examine the ability of viral vectors to transfect the cells of the human vestibular sensory epithelium, we applied replication-incompetent adenoviral vectors that had one viral gene deleted (Ad1) or multiply deleted vectors (Ad2) directly to the culture media at titers that ranged from $10^{5}$ to $10^{9}$ viral particles $/ \mathrm{ml}$ as indicated. Previous work has shown that multiply deleted $(-E 1 a / b$, -E3, -pol, -pTP) adenoviral vectors transfect mammalian inner ear sensory epithelia with minimal toxicity both in vitro $^{3,4}$ and in vivo, ${ }^{5}$ whereas E1a/b-deleted vectors were shown to be toxic to hair cells. ${ }^{6}$ However, we found little difference in infectivity or toxicity between E1a/ b-deleted and multiply deleted vectors (Supplementary Figure 1). Since Ad2 vectors have been shown to yield less toxicity in vivo, ${ }^{5}$ most of our data were acquired using multiply deleted adenoviral vectors. As such, the following paragraphs focus on our results with $\mathrm{Ad} 2$ vectors. A complete list of patient demographics, inner ear tissues, viral vectors, titers and culture times used for this study is found in Table 1. 
Table 1 Adenoviral transfection of human vestibular sensory epithelium

\begin{tabular}{|c|c|c|c|c|c|c|c|}
\hline Patient & Age/gender & Disease & Organ & Viral vector & Titer (viral particles/ml) & Incubation time $(h)$ & Transfection rate (\%) \\
\hline \multirow[t]{2}{*}{1} & \multirow{2}{*}{$61 \mathrm{M}$} & \multirow{2}{*}{$\mathrm{MD}$} & HSCC & Ad2-GFP-Q4 & $3.00 \times 10^{6}$ & 24 & 12 \\
\hline & & & Saccule & Ad2-GFP-Q4 & $3.00 \times 10^{6}$ & 24 & 6.76 \\
\hline 2 & $52 \mathrm{~F}$ & MD & Utricle & Ad2-GFP & $1.00 \times 10^{7}$ & 48 & 46.7 \\
\hline \multirow[t]{3}{*}{3} & \multirow[t]{3}{*}{$45 \mathrm{~F}$} & \multirow[t]{3}{*}{ VS } & SSCC & Ad1-GFP-Q4 & $9.25 \times 10^{9}$ & 96 & 21.3 \\
\hline & & & HSCC & Ad1-GFP-Q4 & $9.25 \times 10^{8}$ & 96 & 30.7 \\
\hline & & & Utricle & Ad2-GFP-Q4 & $3.00 \times 10^{7}$ & 96 & 22.8 \\
\hline \multirow[t]{3}{*}{4} & \multirow[t]{3}{*}{$62 \mathrm{M}$} & \multirow[t]{3}{*}{ VS } & HSCC & Ad2-GFP-Q4 & $3.00 \times 10^{5}$ & 96 & 0.81 \\
\hline & & & PSCC & Ad2-GFP-Q4 & $3.00 \times 10^{7}$ & 96 & 16.2 \\
\hline & & & Saccule & Ad2-GFP-Q4 & $2.25 \times 10^{7}$ & 96 & 10.5 \\
\hline \multirow[t]{3}{*}{5} & \multirow[t]{3}{*}{$64 \mathrm{M}$} & \multirow[t]{3}{*}{ VS } & HSCC & Ad2-GFP-Q4 & $3.00 \times 10^{5}$ & 72 & 0.69 \\
\hline & & & PSCC & Ad2-GFP-Q4 & $3.00 \times 10^{6}$ & 72 & 13.6 \\
\hline & & & Utricle & Ad2-GFP-Q4 & $2.25 \times 10^{7}$ & 72 & 47.5 \\
\hline \multirow[t]{4}{*}{6} & \multirow[t]{4}{*}{$59 \mathrm{~F}$} & \multirow[t]{4}{*}{ VS } & PSCC & Ad2-GFP-Q4 & $3.00 \times 10^{5}$ & 48 & 9.7 \\
\hline & & & HSCC & Ad2-GFP-Q4 & $3.00 \times 10^{6}$ & 48 & 33.3 \\
\hline & & & SSCC & Ad2-GFP-Q̄4 & $1.50 \times 10^{7}$ & 48 & 25.8 \\
\hline & & & Utricle & Ad2-GFP-Q4 & $2.25 \times 10^{7}$ & 48 & 24.9 \\
\hline \multirow[t]{3}{*}{7} & \multirow[t]{3}{*}{$74 \mathrm{M}$} & \multirow[t]{3}{*}{$\mathrm{MD}$} & SSCC & Ad2-GFP-Q4 & $3.00 \times 10^{5}$ & 24 & 2.7 \\
\hline & & & PSCC & Ad2-GFP-Q4 & $3.00 \times 10^{6}$ & 24 & 42.7 \\
\hline & & & Saccule & Ad2-GFP-Q4 & $2.25 \times 10^{7}$ & 24 & 34.2 \\
\hline \multirow[t]{2}{*}{8} & \multirow[t]{2}{*}{$55 \mathrm{~F}$} & \multirow[t]{2}{*}{ VS } & SSCC & Ad2-GFP-Q̄4 & $3.00 \times 10^{6}$ & 12 & 5 \\
\hline & & & PSCC & Ad2-GFP-Q4 & $2.25 \times 10^{7}$ & 12 & 25.9 \\
\hline \multirow[t]{5}{*}{9} & \multirow{5}{*}{$70 \mathrm{~F}$} & \multirow{5}{*}{ VS } & SSCC & & & 120 & \\
\hline & & & HSCC & & & 120 & \\
\hline & & & PSCC & & & 120 & \\
\hline & & & Utricle & & & 120 & \\
\hline & & & Saccule & & & 120 & \\
\hline
\end{tabular}

Abbreviations: HSCC, horizontal semicircular canal; MD, Meniere's disease; PSCC, posterior semicircular canal; SSCC, superior semicircular canal; VS, vestibular schwannoma.

We began by examining the efficacy of a multiply deleted adenoviral vector that carried the gene for green fluorescent protein (GFP) driven by a cytomegalovirus (CMV) promoter (Ad2-GFP). The vector was applied to a cultured human utricle explant for 4 hours at a titer of $10^{7}$ viral particles $/ \mathrm{ml}$. At 48-h post-transfection, the tissue was fixed and stained with Alexa Fluor 546-conjugated phalloidin to illuminate the actin-rich structures just beneath the apical surface of each cell in the epithelium (Figure 2a). The tissue was counterstained with an antibody directed against myosin VIIa, an unconventional myosin expressed by hair cells but not supporting cells. ${ }^{2}$ In the utricle sample shown in Figure 2, there were 134 myosin VIIa-positive hair cells (Figure 2b), 42 of which were also positive for GFP (Figure 2c) which corresponded to a hair cell transfection rate of $31 \%$. In the same field, we counted 210 supporting cells that were GFP-positive but lacked myosin-VIIa staining. Because we did not use an immunolocalization marker for supporting cells, it was difficult to obtain an accurate count for the total number of supporting cells, which prevented us from calculating the transfection rate for supporting cells. Nonetheless, it is clear from Figures $2 b-d$ that the transfection rate for supporting cells was higher than that of hair cells. Figure 2e shows a higher magnification overlay image from a different region of the same epithelium shown in Figures $2 a-d$. We counted 34 cells with partial or full hair bundles; 38 cells that were myosin VIIa-positive; and 32 cells with colocalization of bundles and myosin VIIa. Of those 32 cells, 4 were GFP-positive that corresponded to a hair cell transfection rate of $12.5 \%$. To better view the cell bodies and confirm both hair cell and supporting cell transfection, we generated a vertical projection from a stack of confocal images taken at several focal planes (Figure 2e). Note that when viewed in cross-section, the flask-shaped and cylindrical cell bodies of the respective type I and type II hair cells were apparent and that examples of both cell types were GFP-positive.

Titer and time dependence of adenoviral transfection To determine the relationship between viral titer and transfection rate, we exposed cultured epithelia to Ad2 vectors at titers that ranged between $10^{5}$ and $10^{8}$ viral particles $/ \mathrm{ml}$. The explants were transfected for $24 \mathrm{~h}$ and cultured for 3 days post-transfection at which point the tissue was fixed, stained and examined using confocal microscopy. At titers below $10^{5}$ viral particles $/ \mathrm{ml}$, very few cells were GFP-positive (Figure 3a). At higher titers, many more cells were transfected and expressed GFP (Figures $3 b$ and $c$ ). We were able to achieve transfection rates of $>20-40 \%$ routinely and as high as $47.5 \%$ in one case. Transfection rate for each explant culture was estimated from four to five image fields based on the number of GFP-positive cells, which included both hair cells and supporting cells, divided by the total number of cells. Transfection rate was plotted as a function of viral titer in Figure $3 \mathrm{~d}$. If we assumed it was possible to transfect $100 \%$ of the cells, we were able to fit the data with a Boltzmann curve (line) as described previously, ${ }^{6}$ which allowed us to estimate that a titer of $2.7 \times 10^{7}$ viral particles $/ \mathrm{ml}$ was required to transfect $50 \%$ of the cells. This was remarkably similar to that reported by Holt et al., ${ }^{6}$ who used a similar protocol and found that $4 \times 10^{7}$ viral particles $/ \mathrm{ml}$ were required to transfect half the cells in cultures of the mouse utricle.

The time course of GFP expression was charted by estimating transfection rate as a function of time in 

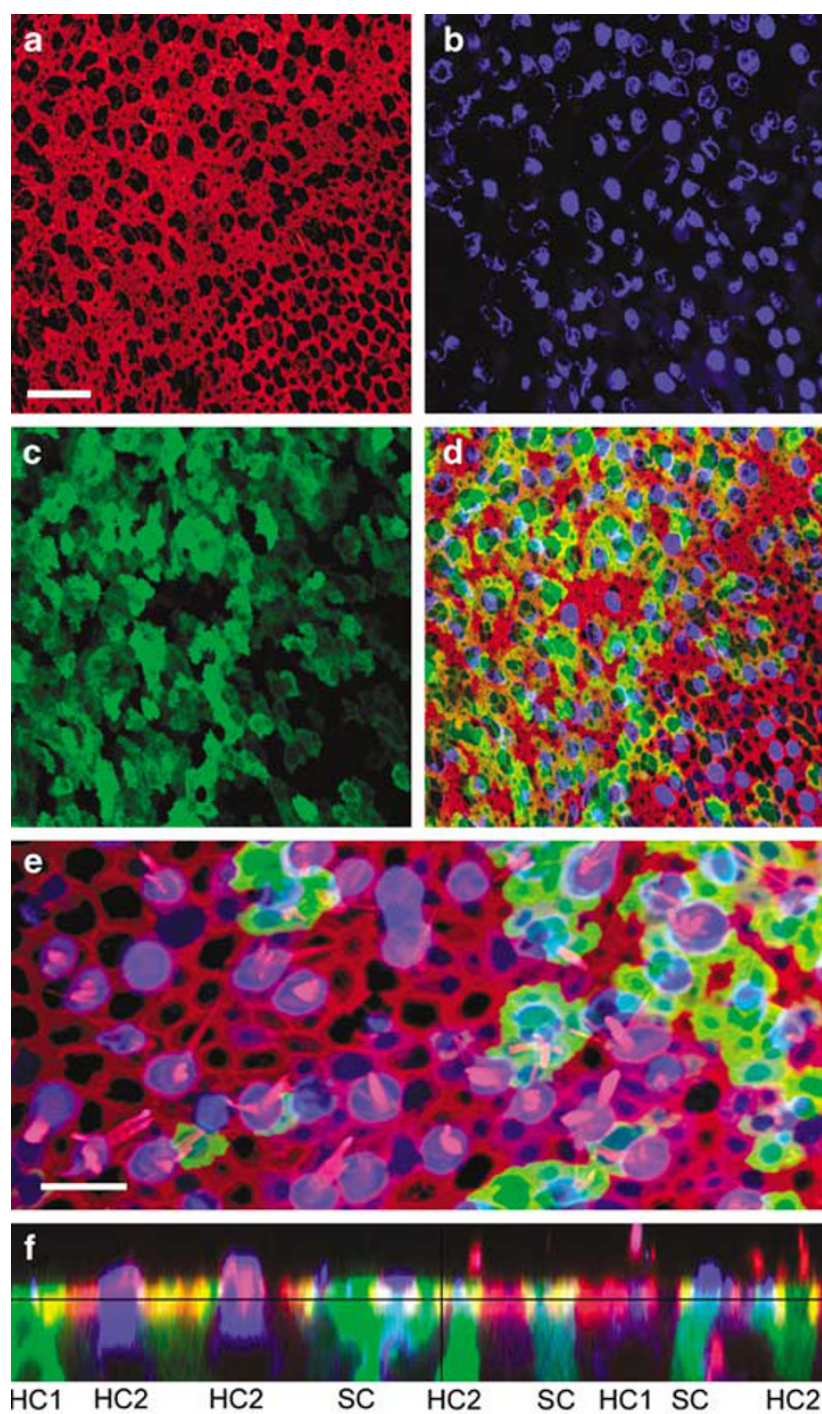

Figure 2 Confocal images of a human utricle harvested from patient \#2. The explant was exposed to $10^{7}$ viral particles $/ \mathrm{ml}$ of Ad2-GFP for $15 \mathrm{~h}$ and maintained in culture for $48 \mathrm{~h}$. The explant was then fixed and stained with Alexa Fluor 546-conjugated phalloidin and an antibody to myosin VIIa and an Alexa Fluor 633-conjugated secondary antibody. Scale bar $=20 \mu \mathrm{m}$ and applies to (a-d) which all show the same image field. (a) A stack of 12 images taken just beneath the apical surface of the epithelium was collapsed to show the cell bodies (b) and the subapical actin (red) that rings each hair cell and supporting cell. (b) Myosin-VIIa immunoreactivity (blue) localizes sensory hair cell cell bodies. (c) Green fluorescence revealed that both hair cells and supporting cells were transfected by the vector and expressed GFP. (d) Merge of panels $(\mathbf{a}-\mathbf{c})$. (e) Higher magnification overlay view from a different region of the same epithelium shown in panels $(\mathbf{a}-\mathbf{d})$. To generate the image a stack of 13 images focused at the hair bundle level was collapsed (red = actin) and overlaid atop a collapsed stack of 10 images focused at the cell body level from the same image field (blue $=$ myosin VIIa; green $=\mathrm{GFP}$ ). Scale bar $=10 \mu \mathrm{m}$. (f) A stack of 19 images projected to reveal a cross-sectional view of the sensory epithelium. Both type I (HC1) and type II hair cells (HC2) and supporting cells were GFP-positive. Myosin VIIa-positive hair cells are also evident. Same color code as for panels $(\mathbf{a}-\mathbf{e})$.

explants exposed to a titer of $3 \times 10^{6}$ viral particles $/ \mathrm{ml}$ for $12-24 \mathrm{~h}$ and then maintained in culture for up to 4 days (Figure 4). We noticed faint but unmistakable GFP fluorescence as early as $12 \mathrm{~h}$ after the initiation of viral transfection. Over the first $24 \mathrm{~h}$, there was a rapid rise in both the intensity of GFP fluorescence and the number of GFP-positive cells (Figure 4a). Transfection rates plateaued within the first $36 \mathrm{~h}$ and remained relatively stable at 48 and $72 \mathrm{~h}$ post-transfection (Figures $4 \mathrm{~b}$ and c). There was a statistically insignificant decline $(P>0.2)$ at $96 \mathrm{~h}$ post-transfection, perhaps due to a decline in expression of the transgene or alternatively, a loss of cells due to the prolonged culture time. Transfection rates at times greater than $96 \mathrm{~h}$ post-transfection were not tested. Transfection rates at five intervals were plotted as a function of time after the onset of viral transfection (Figure 4d) and the data were fit with an exponential equation that reached a steady-state transfection rate of $26.5 \%$ with a time constant of $6.5 \mathrm{~h}$ (line).

\section{Viral transfection of a deafness gene}

To assess the ability of adenovirus to transfect and express a functionally relevant gene in human inner ear sensory epithelia, we designed a vector that carried GFP and the wild-type form of the potassium channel gene KCNQ4. When mutated, KCNQ4 causes a dominantprogressive hearing loss in humans known as DFNA2. ${ }^{7}$ The vector was designed to drive expression of GFP and KCNQ4 independently with two distinct CMV promoters. We began by examining the expression pattern of endogenous KCNQ4 using immunolocalization with an antibody specific to KCNQ4 (Figure 5). The pattern of fluorescence suggested that KCNQ4 expression was restricted to hair cells, type I cells in particular (Figure 5c). Previously, Oghalai et al. ${ }^{8}$ recorded potassium currents from type I and type II hair cells harvested from human vestibular organs and showed that type I cells expressed a low-voltage-activated current, termed $I_{\mathrm{K}, \mathrm{L}}$. In rodents, it has been suggested that $I_{\mathrm{K}, \mathrm{L}}$ in type I cells and similar currents, known as $I_{K, \mathrm{n}}$ in auditory outer hair cells, are carried by KCNQ4 channels.9,10 Based on the similar physiological expression pattern of $I_{\mathrm{K}, \mathrm{L}}$ between rodents and humans and the similar pattern of KCNQ4 immunolocalization shown here, we suggest that $I_{\mathrm{K}, \mathrm{L}}$ may be carried by KCNQ4 in humans as well.

We transfected cultured human sensory epithelia for 1-3 days after exposure to $10^{6}-10^{8}$ viral particles $/ \mathrm{ml}$ of Ad2-GFP-Q4. The explants were then fixed and stained for KCNQ4 and actin and imaged with confocal microscopy (Figure 6) focused just beneath the apical surface of the sensory epithelium. We counted 596 total cells in Figure 6a, which included supporting cells and both type I and type II hair cells. Of those, 103 were GFP-positive (Figure 6b), which corresponded to a transfection rate of $17.3 \%$. A total of 158 cells were KCNQ4-positive (Figure 6c). The KCNQ4 antibody could not distinguish between endogenous KCNQ4 and the exogenous virally expressed KCNQ4, therefore we present the following numerical argument as evidence that Ad2GFP-Q4 efficiently transfected and drove expression of exogenous KCNQ4. We estimated the expression rate of total KCNQ4 to be $26.5 \%(158 / 596)$ which includes cells with endogenous expression alone, cells with exogenous expression alone and cells with both. If we assume the vector had no particular tropism for cells that express endogenous KCNQ4 and we conservatively overestimate that the endogenous $\mathrm{KCNQ} 4$ expression rate is equal to the total KCNQ4 expression rate, we can make the following prediction. In tissue exposed to a vector that 

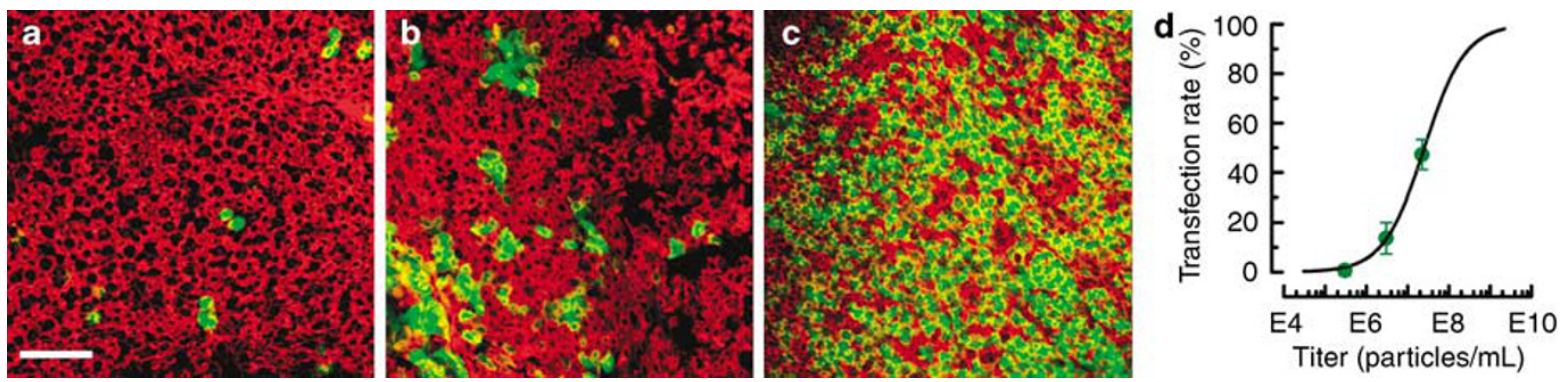

Figure 3 Representative confocal images generated from stacks of 12 images taken just beneath the apical surface of human vestibular sensory epithelia excised from patient \#5. Tissue was transfected with Ad2-GFP-Q4 at the titer indicated below for $24 \mathrm{~h}$ and fixed $72 \mathrm{~h}$ posttransfection and stained with Alexa Fluor 546 phalloidin. Each image shows the fluorescence overlay for GFP (green) and actin (red). Scale $\mathrm{bar}=20 \mu \mathrm{m}$ and applies to (a-c). (a) Horizontal semicircular canal exposed to $3 \times 10^{5}$ viral particles/ml. (b) Posterior semicircular canal exposed to $3 \times 10^{6}$ viral particles $/ \mathrm{ml}$. (c) Utricle exposed to $2.3 \times 10^{7}$ viral particles $/ \mathrm{ml}$. (d) Transfection rate was estimated from the number of GFP-positive cells divided by the number of total cells. Each data point was generated by calculating the mean transfection rate from 4 to 5 images taken from a single epithelium. Error bars show s.e.m. $(n=4-5)$. The data were plotted as a function of viral titer (circles) and fitted with a Boltzmann relation that revealed a titer of $2.7 \times 10^{7}$ viral particles $/ \mathrm{ml}$ which corresponded to a transfection rate of $50 \%$.
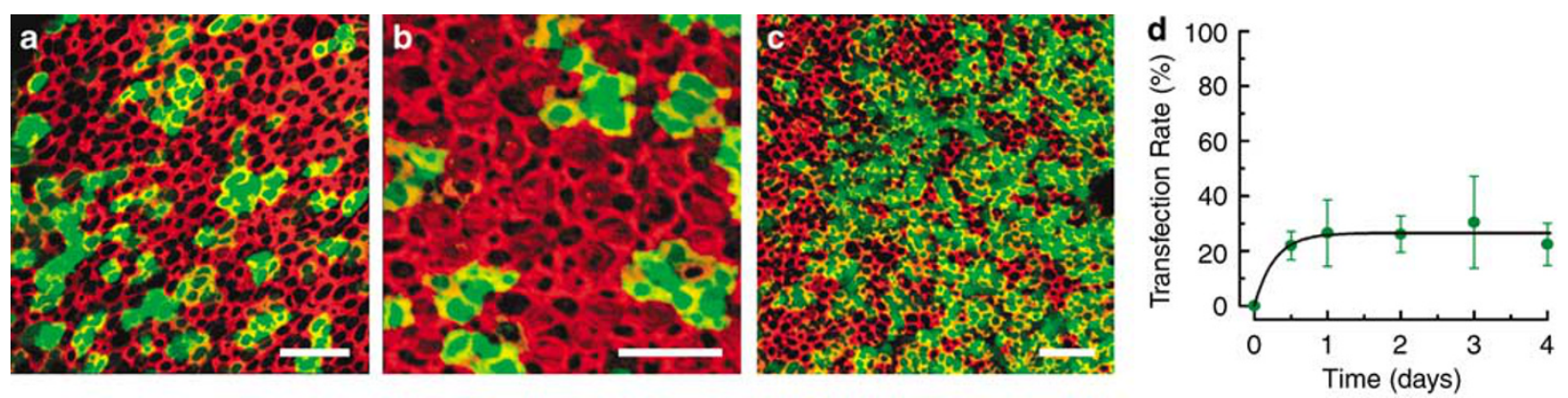

Figure 4 Representative images generated from stacks of confocal images taken just beneath the apical surface of tissue harvested from several patients, exposed to $2.3 \times 10^{7}$ viral particles/ml of Ad2-GFP-Q4 for $24 \mathrm{~h}$. The explants were maintained in culture as indicated below, fixed and stained with Alexa Fluor 546 phalloidin. Each image shows the fluorescence overlay for GFP (green) and actin (red). The scale bar in each image equals $20 \mu \mathrm{m}$. (a) Saccule (patient 7) 1 day post-transfection. (b) Utricle (patient 6) 2 days post-transfection. (c) Utricle (patient 5) 3 days post-transfection. (d) Transfection rate was estimated from the number of GFP-positive cells divided by the number of total cells. The data were plotted as a function of time post-transfection (circles). Error bars show the s.e.m. $(n=2-5)$. The data were fit with an exponential equation (line) that reached a steady-state transfection rate of $26.5 \%$ with a time constant of $6.5 \mathrm{~h}$.

carries only GFP, $26.5 \%$ of the GFP-positive cells should also be positive for KCNQ4. However, in our experiment the vector carried the genes for both GFP and KCNQ4 and we found that $78.6 \%(81 / 103)$ of the cells that were positive for GFP were also positive for KCNQ4. Thus, we conclude that the significant increase in the KCNQ4 expression rate in GFP-positive cells must represent exogenous, virally expressed KCNQ4. Overall we estimate successful expression of exogenous KCNQ4 in $\sim 10 \%$ of the cells.

Figure $7 \mathrm{a}$ shows a single focal plane at higher magnification from a different region of the same epithelium shown in Figure 6. Both GFP- and KCNQ4positive (red) cells were visible. In cross-section, their morphologies appeared consistent with hair cell and supporting cell morphologies, which have round and more stellate cell bodies, respectively. To view transfected cells in vertical sections, we generated a projection from a stack of 22 images from the same epithelial field shown in Figure 7a. Both hair cells and supporting cells were GFP-positive and both type I and type II hair cells expressed KCNQ4. Lastly, we note that the distribution of KCNQ4 fluorescence indicated that the ion channel protein was localized to the basolateral membrane of the cells, which suggested that the virally expressed protein was properly targeted to the appropriate subcellular location.

\section{Discussion}

\section{Cell viability and availability}

We successfully harvested 26 of 45 possible vestibular end organs from nine patients, which corresponded to a success rate of $57.8 \%$ and compared favorably to previous reports ${ }^{11}$ with a $40 \%$ success rate. ${ }^{12}$ Further refinement in the harvest and culture technique may increase the overall yield of vestibular tissue and will need to address the difficulties associated with removal of the dense otic capsule bone while still preserving the underlying vestibular epithelia; excision of the ampullae and maculae from their neuronal attachments and bony cradle; methods for transfer of the tissue from the patient to the specimen cup, all in a timely manner while not damaging the particularly fragile sensory hair bundles; and optimization of culture conditions.

Following the successful harvest of the human vestibular sensory epithelia, we demonstrated the viability of inner ear sensory epithelia in culture by examining cellular morphology with DIC microscopy, by 
cytoarchitecture, including hair bundle structure under confocal microscopy, by expression of the hair cell genes myosin VIIa and KCNQ4 and by the ability of adenoviral vectors to transfect the tissue and drive protein synthesis and expression of both a reporter and a functionally relevant protein. Our results demonstrate that harvested tissue can be maintained in culture up to 5 days and perhaps longer since greater times were not tested.

The majority of epithelia harvested for this study were excised from six patients undergoing surgery for vestibular schwannoma. With an incidence of $0.2-1$ per $100000,{ }^{13,14}$ vestibular schwannoma is rare, but the translabyrinthine approach for resection of these benign tumors offers a reliable and steady supply of viable human tissue without risk of injury to the patient. Before
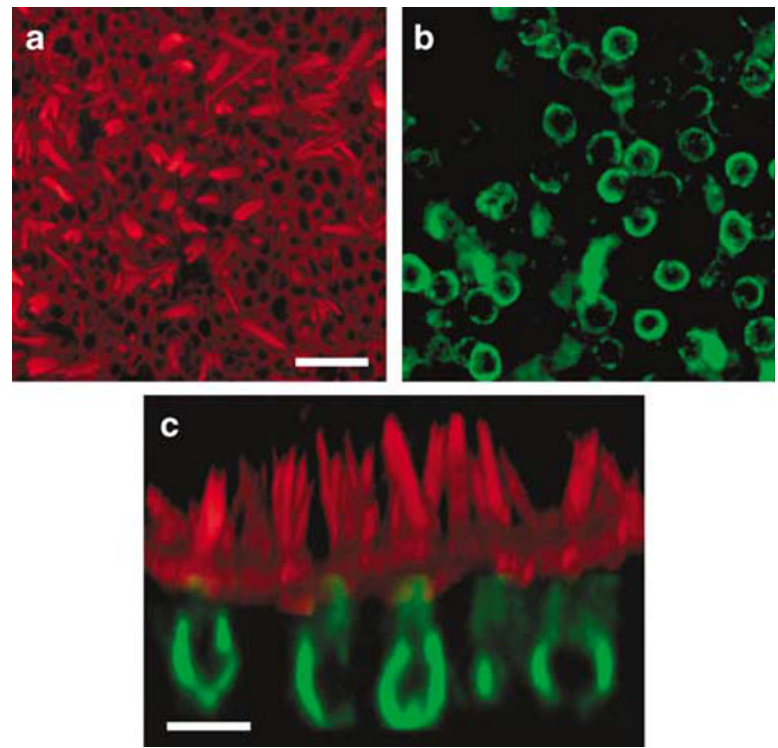

Figure 5 Confocal images of a saccule harvested from patient \#1. The explant was cultured for $24 \mathrm{~h}$, fixed and stained with Alexa Fluor 546 phalloidin (red) and endogenous KCNQ4 (green). (a) A view from just above the apical surface of the epithelium reveals the actin-rich hair bundles. Scale $\mathrm{bar}=25 \mu \mathrm{m}$ and applies to panels (a) and (b). (b) An image focused at the cell body level revealed the endogenous pattern of KCNQ4 expression. (c) Cross-sectional projection of the saccule generated from a stack of 43 images focused every $1.0 \mu \mathrm{m}$. The actin and KCNQ4 channels were merged. Scale bar $=10 \mu \mathrm{m}$. this study, the condition of the vestibular end organs was unknown. Since the tumor grows from the vestibular nerve more proximal to the brain, transmission of afferent vestibular signals is blocked which prevents clinical assessment of vestibular end-organ function. However, our results indicate that some sensory cells and supporting cells within the vestibular end organs remain viable which suggests that future therapies that spare the vestibular nerve may allow for recovery of vestibular function in these patients.

Vestibular epithelia were also harvested from patients undergoing labyrinthectomy for Meniere's disease (patients 1, 2 and 7), in which case the vestibular apparatus may have been diseased. Histologically, Meniere's disease is characterized by endolymphatic hydrops and swelling of the endolymphatic space of the inner ear, ${ }^{15}$ but the etiology and pathophysiology of endolymphatic hydrops are unknown. ${ }^{16}$ Whether the swelling affects or injures the vestibular end organs is also unknown, but many patients with Meniere's disease have vestibular deficits as assessed by electronystagmography. Despite the possibility of altered or injured vestibular end organs in the Meniere's patients, we found that the vestibular epithelia were viable, could be maintained in culture and could be transfected with adenovirus.

The implications of these findings are twofold. First, our results suggest that both vestibular schwannoma and Meniere's patient populations can provide tissue for the in vitro study of reagents designed to treat inner ear dysfunction, and second, that both healthy and potentially diseased tissue can be targeted by gene-transfer reagents. While the in vitro model system we present here cannot address important in vivo questions, such as functional recovery of whole organ systems or systemic or immunogenic toxicity, we suggest that it can be used as a powerful tool to study the efficacy of potential therapeutic reagents to target the appropriate cell type within the human sensory epithelium; to examine their ability to restore gene and cell function; or to evaluate their capacity to promote the generation of new hair cells or supporting cells. While animal models have offered important contributions to our understanding of inner ear function and dysfunction, we suggest that our in vitro model system of the human inner ear will allow those discoveries to be further refined and properly targeted to treat inner ear disorders in humans.
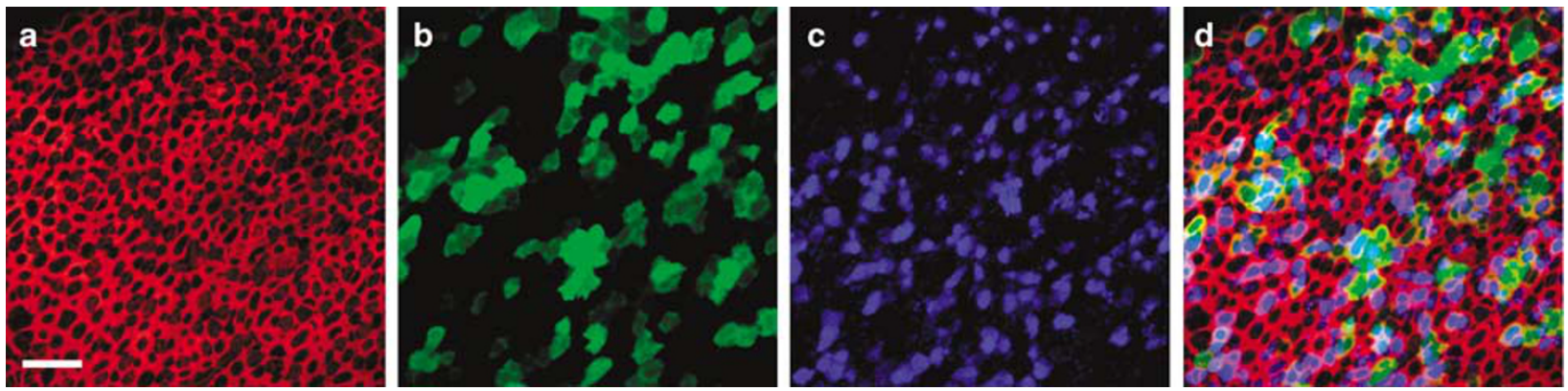

Figure 6 Stacks of confocal images taken just beneath the apical surface were used to generate images of the saccule harvested from patient \#7. The explant culture was exposed to $2.3 \times 10^{7}$ viral particles $/ \mathrm{ml}$ of Ad2-GFP-Q4 for $24 \mathrm{~h}$, fixed and stained with Alexa Fluor 546 phalloidin (red) and KCNQ4 (blue) and GFP (green). The scale bar represents $20 \mu \mathrm{m}$ and applies to all images. The same field and focal planes are shown in images (a-d). (a) An image just beneath the apical surface of the epithelium shows the actin that rings each cell. (b) A total of 103 GFPpositive cells are evident in this field. (c) The KCNQ4 antibody labeled both endogenous hair cell KCNQ4 and exogenous virally expressed KCNQ4. (d) Merge of panels a-c shows colocalization of GFP and KCNQ4 in $78.6 \%$ of the cells. 

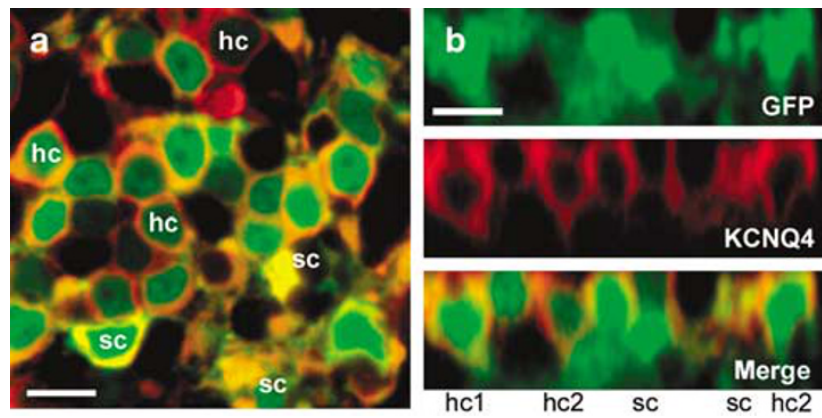

Figure 7 Confocal images of the saccule harvested from patient \#7 (same tissue sample shown in Figure 6). The explant culture was exposed to $2.3 \times 10^{7}$ viral particles/ml of Ad2-GFP-Q4 for $24 \mathrm{~h}$, fixed and stained. (a) A magnified view of a single focal plane $6 \mu \mathrm{m}$ beneath the apical surface of the saccule. Note that both KCNQ4positive (red) and green fluorescent protein (GFP)-positive (green) cells with morphologies consistent hair cells and supporting cells are apparent in the image. Hair cell (hc) and supporting cell (sc) morphologies are indicated on the image. Scale bar $=10 \mu \mathrm{m}$. (b) Cross-sectional projection generated from a stack of 22 images focused every $1.0 \mu \mathrm{m}$ from the same image field shown in panel (a). Scale bar $=10 \mu \mathrm{m}$. Note that both type I (hc1) and type II (hc2) hair cell morphologies are apparent.

\section{Adenovirus transfects the human sensory epithelium}

Adenovirus can mediate gene transfer into various inner ear cell types, including hair cells and supporting cells and has been demonstrated in several mammalian models, including the guinea pig, ${ }^{5,17-24}$ mouse ${ }^{6,25-28}$ and rat. $^{29,30}$. As such, we tested three adenoviral vectors for their ability to transfect human vestibular epithelia in vitro. We tested vectors with a single gene deleted and with multiple genes deleted and found that both vector designs transfected sensory epithelial cells. Previously, E1a/b-deleted vectors were shown to be toxic to mouse vestibular hair cells, ,5,6 but multiply deleted adenoviral vectors were found to have reduced or no hair cell toxicity. ${ }^{3-5}$ We did not detect any direct toxic effects on the cultured cells for either the E1a/b-deleted or the multiply deleted adenoviral vectors, but chose to focus our work on multiply deleted vectors since these would most likely have reduced toxicity in vivo. Although cellular morphology of transfected cells appeared similar to that of neighboring nontransfected cells and transfected cells were able to synthesize the exogenous protein and remain viable for up to 4 days, studies in which cell physiology, including measurement of mechanotransduction in human hair cells before and after viral transfection, will be required to more directly address vector toxicity.

For this study, the vectors all carried GFP as a reporter gene, which allowed for ease of detection under fluorescence and confocal microscopy. ${ }^{31}$ We found that vestibular sensory epithelial cells from all three semicircular canals and the two otolithic organs demonstrated moderate to high intensity GFP fluorescence which was easily distinguished from the minimal background autofluorescence. We found that transfection rate varied as a function of viral titer and that we were able to achieve transfection rates as high as $47.5 \%$ with titers of $2.3 \times 10^{7}$ viral particles $/ \mathrm{ml}$. We presume that at higher titers, higher transfection rates can be achieved. We also noticed that the onset of transgene expression began as early as $12 \mathrm{~h}$ after exposure to the vector. Transfection rate stabilized within $24 \mathrm{~h}$ and remained stable out to 4 days. Longer times were not tested. In other systems, adenovirus tends to drive only transient expression of the exogenous gene. ${ }^{32,33}$ For some potential gene therapy strategies, such as transdifferentiation of supporting cells into hair cells using the hair cell transcription factor Math1, ${ }^{34,35}$ transient expression that mimics the temporal expression pattern of endogenous genes may be advantageous.

Based on morphology of the transfected cells and coexpression with the hair cell-specific protein myosin VIIa or lack of coexpression, we identified both supporting cells and hair cells that were GFP-positive, which suggested that either could be gene therapy targets. Furthermore, we noted that both type I and type II hair cells were transfected. Future experiments focused on vector design may allow for specific targeting of only supporting cells, only hair cells, or perhaps only type I or type II cells. For example, use of cell type-specific promoters such as the hair cell-specific myosin-VIIa promoter, $^{36}$ might allow for more selective transgene expression. Alternatively, manipulation of the viral capsid or selection of another vector type might allow for transfection of a specific subset of inner ear cell types.

Uptake of adenovirus requires binding of the viral capsid to the coxsackie-adenovirus receptor (CAR). ${ }^{37,38}$ Our demonstration of adenoviral transfection in human sensory epithelia suggests CAR receptors are present in the mature human inner ear and supports the development of adenovirus, or other vectors that bind the CAR receptor, for future human application.

Several other viral vectors have been shown to transfect hair cells and/or supporting cells of the mammalian inner ear, ${ }^{3}$ including herpes simplex virus type $1,{ }^{39}$ vaccinia virus, ${ }^{39}$ lentivirus ${ }^{40}$ and adeno-associated virus ${ }^{41}$ and thus may also be suitable candidates for development as inner ear gene-therapy reagents. Each vector has its own profile of infectivity, tropism for the various cell types of the inner ear, host immune response, toxicity, duration and stability of infectivity, integration into the host genome and gene capacity, all of which must be taken into consideration for suitable vector selection and design. ${ }^{25,42,43}$

\section{Expression of deafness genes}

We examined the endogenous expression pattern of two hair cell genes known to cause inner ear dysfunction when mutated. Consistent with previous studies in lower mammals, ${ }^{2}$ we found that myosin VIIa was expressed in hair cells. We never observed myosin VIIapositive cells that had a supporting cell morphology. Likewise, many myosin VIIa-positive cells also had prominent hair bundles. As such, we were confident in our use of Myosin VIIa as a hair cell marker. Myosin VIIa is localized throughout the hair bundle and cell body, but its precise role in hair cells remains controversial. Nonetheless, it is clear that myosin VIIa plays a critical role in hair bundle structure and function ${ }^{44}$ and probably performs other important tasks elsewhere. Indeed, mutations in myosin VIIa cause both dominant and recessive forms of deafness including, Usher's syndrome type $1 \mathrm{~B}$ which is characterized by deafness, balance disorders and blindness. Our finding that adenovirus can transfect myosin VIIa-positive cells raises the possibility that wild-type myosin VIIa could be trans- 
fected into hair cells to rescue inner ear function in patients who suffer from Usher's syndrome 1B. Furthermore, since we have demonstrated that Myosin VIIa is expressed in hair cells but not supporting cells, we suggest that the human Myosin-VIIa promoter could be engineered into gene therapy vectors to drive hair cellspecific expression in the human inner ear.

We also examined the endogenous expression pattern of the potassium channel gene, KCNQ4, which when mutated causes the nonsyndromic, dominant-progressive hearing loss, DFNA2. ${ }^{7}$ In mice, KCNQ4 has been shown to be expressed exclusively in the auditory and vestibular systems, and in particular, in auditory and vestibular hair cells. ${ }^{10,45}$ Furthermore, it has been suggested that potassium channels that consist of KCNQ4 subunits carry the ionic currents known as $I_{K, \mathrm{n}}$ and $I_{\mathrm{K}, \mathrm{L}}$ in auditory and vestibular hair cells, respectively. ${ }^{9}$ We found robust expression of KCNQ4 in human hair cells, including type I cells. In a previous study, Oghalai et al. ${ }^{8}$ recorded $I_{\mathrm{K}, \mathrm{L}}$-type currents in human type I vestibular hair cells. Based on the colocalization of KCNQ4 and $I_{\mathrm{K}, \mathrm{L}}$ in human type I cells, we suggest that KCNQ4 may be the molecular correlate of $I_{\mathrm{K}, \mathrm{L}}$ in human vestibular organs and perhaps $I_{\mathrm{K}, \mathrm{n}}$ in the human auditory organ as well. If so, we propose that it is the loss of $I_{\mathrm{K}, \mathrm{L}}$ and $I_{K, \mathrm{n}}$ in patients who carry KCNQ4 mutations that causes the DFNA2 phenotype.

To begin to examine the feasibility of gene therapy in human inner ear hair cells, we generated adenoviral vectors that carried the wild-type form of KCNQ4. We reasoned that overexpression of the exogenous wild-type protein might restore ion channel function in patients who carry KCNQ4 mutations and suffer from DFNA2 deafness. We found significantly higher expression rates of KCNQ4 in GFP-positive cells, which provided strong evidence that Ad2-GFP-Q4 was able to transfect and drive expression of exogenous KCNQ4. Although we did not confirm that the exogenous protein was functional, we noted that the protein was appropriately targeted to the basolateral membranes of cells within the sensory epithelium. By examining KCNQ4 immunofluorescence in GFP-positive supporting cells, we were able to determine, qualitatively, that the vector was capable of driving equal or greater levels of exogenous KCNQ4 expression relative to the endogenous KCNQ4 expression we observed in GFP-negative hair cells. The ability of a vector to overexpress wild-type transgenes will be an important criterion for gene therapy reagents designed to rescue inner ear deficits that result from dominant mutations. Alternatively, strategies for overcoming dominant mutations might include design and introduction of mutation-selective siRNAs to silence the mutant but not wild-type allele.

\section{Conclusions}

We have found that human sensory epithelia harvested from aged, adult vestibular organs are robust and contain viable hair cells and supporting cells that can be maintained in an organotypic explant culture for up to 5 days and perhaps longer. Although the tissue harvest is difficult and depends upon a limited patient population, we propose that our in vitro preparation presents a novel experimental paradigm that may facilitate the translation of fundamental discoveries from inner ear biology into new clinical strategies for treating inner ear disorders. We envision that both gene therapy and pharmacologic strategies designed to treat either genetic inner ear disorders or acquired, age-related hearing loss and vestibular dysfunction can be tested with our in vitro model system before the initiation of clinical trials. Lastly, the recent reports that adenoviral vectors that carry the hair cell transcription factor, Math1, can restore auditory function in deafened guinea pigs ${ }^{35}$ and vestibular function in mice, ${ }^{46}$ taken together with our results that show adenovirus can transfect both hair cells and supporting cells in adult human inner ear sensory epithelia, suggest a sound future for inner ear gene therapy.

\section{Materials and methods}

\section{Tissue harvest and culture}

Our protocol for harvesting human inner ear tissue was approved by the University of Virginia Institutional Review Board (Protocol \#11195). Patients undergoing translabyrinthine removal of vestibular schwannomas or labyrinthectomy for Meniere's disease were consented for use of their tissue in this experimental protocol. The tissue was carefully harvested at the time of labyrinthectomy for Meniere's disease or the labyrinthectomy portion of the translabyrinthine approach for removal of vestibular schwannoma as described previously. $8,12,11$ All dissections were performed at room temperature under normal saline. Using an otologic drill, otic capsule bone was removed from the ampullated ends of the semicircular canals. The ampulla of each semicircular canal was identified, and, using a sharp Rosen needle or round knife, dissected from its bony cradle in the bony semicircular canal. The membranous duct was sharply divided, and the sensory epithelia were teased away from their neuronal attachments. Once freed, the tissue was placed on a small, saline-soaked piece of Telfa (Kendall, Johnson and Johnson, NJ, USA) and immediately placed in a specimen cup containing MEM (Invitrogen, Gibco, Grand Island, NY, USA) supplemented with $10 \mathrm{mM}$ HEPES (Sigma, St Louis, MO, USA) and $0.05 \mathrm{mg} / \mathrm{ml}$ ampicillin (MEM/HEPES/Amp). The vestibule was opened next with the otologic drill. The maculae of the utricle and saccule were identified and dissected from the underlying otic capsule bone. Neuronal and fibrous attachments were sharply divided, and the tissue was transferred onto the wet Telfa and quickly placed in a specimen cup with MEM/HEPES/ Amp under sterile conditions.

Each vestibular end organ was placed in its own specimen cup with MEM/HEPES/Amp and transported from the surgical arena to the laboratory. The end organs were microdissected to remove accessory structures so that just the sensory epithelia were retained. Each sensory epithelium was mounted on a $22 \mathrm{~mm}$ round glass coverslip and pinned beneath two glass fibers glued at one end approximately $1-1.25 \mathrm{~mm}$ apart (Figure 1). The tissue samples were transferred to 12-well plates (Nunclon, Roskilde, Denmark) with one epithelium/well and bathed in $2 \mathrm{ml} \mathrm{MEM/HEPES/Amp.} \mathrm{The}$ explants were then placed in a conventional tissue culture incubator at $37^{\circ} \mathrm{C}, 5 \% \mathrm{CO}_{2}$ and $>50 \%$ relative humidity and maintained for up to 5 days. Explant cultures were exposed to adenoviral vectors and titers as indicated in 
the text and Table 1 . Vectors were added directly to the culture media for 4-24 h. After $24 \mathrm{~h}$, the culture medium was switched to Opti-MEM (Invitrogen) supplemented with $0.05 \mathrm{mg} / \mathrm{ml}$ ampicillin and was exchanged with fresh solution every $24 \mathrm{~h}$ thereafter.

\section{Generation of adenoviral vectors}

Three replication-deficient adenoviral vectors were used for these experiments: one first-generation (Ad1) vector that had a single viral gene deleted $\left(\mathrm{E} 1 \mathrm{a} / \mathrm{b}^{-}\right)$and two second-generation (Ad2) multiply deleted (E1- ${ }^{-}, 3^{-}$, $\mathrm{pol}^{-} \mathrm{pTP}^{-}$) vectors. The Ad1 vector was generated by the Wilmer Vector Production Unit at Johns Hopkins University as described previously. ${ }^{6,47}$ Briefly, to generate Ad1-GFP-Q4, the coding sequence of the wild-type form of human KCNQ4 (a generous gift from Dr Thomas Jentsch) was subcloned into the pAdcgi shuttle vector which contained a bicistronic expression cassette that included a CMV promoter followed by the gene for GFP, an internal ribosome entry sequence and a multiple cloning site. A total of $60-70 \%$ confluent CRE8 cells were transfected with $\Psi 5$ viral DNA and pAdcgi using $12 \mu \mathrm{l}$ Lipofectamine reagent in $300 \mu \mathrm{l}$ Opti-MEM. The cells were grown for $\sim 1$ day or until cytopathic effects were observed. Cells were then ruptured with several freeze/ thaw cycles in dry ice ethanol and $37^{\circ} \mathrm{C}$ and spun down in a clinical centrifuge at 1500-2000 r.p.m. One milliliter of the supernatant was added to a T25 flask of $85-90 \%$ confluent CRE8 cells, incubated for 2-3 days and harvested. This cycle was repeated two to three times as needed. After the final freeze/thaw cycle and centrifugation, the supernatant was loaded onto a three-part step gradient of $1.25,1.33$ and $1.45 \mathrm{~g} / \mathrm{ml} \mathrm{CsCl}$ and spun in a swinging bucket rotor at 40-50 $\mathrm{g}$ for $1 \mathrm{~h}$ at $14^{\circ} \mathrm{C}$. The viral band was transferred to a test tube on ice and dialyzed against $10 \mathrm{mM}$ Tris $\mathrm{pH} 7.4,0.9 \% \mathrm{NaCl}$, $1 \mathrm{mM} \mathrm{MgCl}_{2}$ and $1 \mathrm{mM} \mathrm{CaCl}_{2}$ at $4{ }^{\circ} \mathrm{C}$ for $4-16 \mathrm{~h}$ to remove the cesium. Finally, virus was removed, 1/10 volume glycerol added, aliquotted and stored at $-80^{\circ} \mathrm{C}$.

Ad2-GFP was a generous gift from Dr Andrea Amalfitano. ${ }^{48}$ Ad2-GFP-Q4 was generated by subcloning the wild-type form of mouse KCNQ4 into the multiple cloning site of pAdTrack-CMV, ${ }^{49}$ which contains two independent CMV promoters, one that drives expression of GFP and the second that, in this case, drives expression of KCNQ4. The pAdtrack-CMV-Q4 shuttle vector was digested with PmeI and co-transfected with pAdeasy- $\Delta$ pol $^{50}$ into Escherichia coli BJ5183 cells to generate pAdeasy- $\Delta$ pol-GFP-Q4. To confirm homologous recombination, kanamycin-resistant clones were screened with a PacI digestion. The recombinant clone, pAdeasy- $\Delta$ pol-GFP-Q4 was transformed into $E$. coli DH10B cells and purified using an Eppendorf Perfectprep Mini Kit (Eppendorf North America, Westbury, NY, USA). The pAdeasy- $\Delta$ pol-GFP-Q4 recombinant adenoviral plasmid was PacI digested and transfected into E1, E3, pol pTP transcomplementing C7 cells. ${ }^{50}$ Large-scale amplification was achieved through six serial expansions of viral lysate in C7 cells. Ad2-GFP-Q4 was purified with a BD Adeno-X Purification Kit (BD Biosciences Clontech, San Jose, CA, USA) and further concentrated using Amicon Ultra-15 100000 MWCO centrifugal filters (Millipore Corporation, Billerica, MA, USA), aliquotted and stored at $-80^{\circ} \mathrm{C}$. The effective viral titer was estimated from the number of GFP-positive HEK293 cells $12-18 \mathrm{~h}$ after transfection with serial dilutions of concentrated viral stock. The stock titer was $1.2 \times 10^{9}$ viral particles $/ \mathrm{ml}$.

\section{Immunohistochemistry}

After $12 \mathrm{~h}$ to 4 days in culture, the explant cultures were fixed for $10 \mathrm{~min}$ in $4 \%$ paraformaldehyde dissolved in phosphate-buffered saline (PBS). The samples were rinsed three times in PBS and exposed to $0.1 \%$ Triton X-100/PBS for 15 min. After three more rinses in PBS, a block solution containing 3\% bovine serum albumin and $3 \%$ normal goat serum in PBS was applied for $1 \mathrm{~h}$ The tissue was exposed to either anti-Myosin 7a (a gift from Dr Tama Hasson) or anti-KCNQ4 (a gift from Dr Bechara Kachar) diluted $1: 1000$ in the block solution and incubated overnight at $4^{\circ} \mathrm{C}$ in a 12-well humidified chamber. The next day, the tissue was rinsed four times (10 min.) in a mild detergent $(0.05 \%$ Tween 20$)$ followed by application of the secondary antibody, a goat antirabbit IgG conjugated to Alexa Fluor 633 at a dilution of 1:200. The tissue was counterstained with Alexa Fluor 546 phalloidin also at 1:200. The tissue was rinsed again several times in the $0.05 \%$ Tween 20 and embedded in Fluoroguard and mounted on glass slides and imaged on a Zeiss LSM 510 confocal microscope (Carl Zeiss, Oberkochen, Germany) with varying objectives $(\times 20$, $\times 40$ and $\times 63$ oil). GFP fluorescence was imaged with a band-pass emission filter of 505-530 BP nm; Alexa Fluor 546 and Alexa Fluor 633 were imaged with a 560-615 nm band-pass filter and a $650 \mathrm{~nm}$ long-pass filter, respectively. Images were acquired at several focal planes throughout the tissue ( $\mathrm{z}$ series) and recorded with Zeiss LSM software. In some tissue samples, broad-spectrum autofluorescence was apparent in all three channels and was digitally subtracted post hoc. Adobe Photoshop.cs (Adobe Systems Inc., San Jose, CA, USA) and LSMib (Carl Zeiss, Oberkochen, Germany) software packages were used for image analysis.

\section{Acknowledgements}

We thank Dr Thomas Jentsch and Dr Kirk Biesel for providing the coding sequence of the human and mouse KCNQ4 genes, respectively. We also thank Dr Andrea Amalfitano for providing Ad2-GFP, Dr Bechara Kachar for the KCNQ4 antibody and Dr Tama Hasson for the myosin-VIIa antibody. This work was supported by the NIH/NIDCD Grant \#DC005439 to JR Holt, the Virginia Lion's Hearing Foundation and a Triological Society Career Development Grant to BW Kesser.

\section{References}

1 Petit C. From deafness genes to hearing mechanisms: harmony and counterpoint. Trends Mol Med 2006; 12: 57-64.

2 Hasson T, Gillespie PG, Garcia JA, MacDonald RB, Zhao Y, Yee AG et al. Unconventional myosins in inner-ear sensory epithelia. J Cell Biol 1997; 137: 1287-1307.

3 Holt JR. Viral-mediated gene transfer to study the molecular physiology of the mammalian inner ear. Audiol Neurootol 2002; 7: 157-160.

4 Corey DP, Garcia-Anoveros J, Holt JR, Kwan KY, Lin SY, Vollrath MA et al. TRPA1 is a candidate for the mechanosensitive 
transduction channel of vertebrate hair cells. Nature 2004; 432: 723-730.

5 Luebke AE, Steiger JD, Hodges BL, Amalfitano A. A modified adenovirus can transfect cochlear hair cells in vivo without compromising cochlear function. Gene Ther 2001; 8: 789-794.

6 Holt JR, Johns DC, Wang S, Chen ZY, Dunn RJ, Marban E et al. Functional expression of exogenous proteins in mammalian sensory hair cells infected with adenoviral vectors. J Neurophysiol 1999; 81: 1881-1888.

7 Kubisch C, Schroeder BC, Friedrich T, Lutjohann B, El-Amraoui A, Marlin S et al. KCNQ4, a novel potassium channel expressed in sensory outer hair cells, is mutated in dominant deafness. Cell 1999; 96: 437-446.

8 Oghalai JS, Holt JR, Nakagawa T, Jung TM, Coker NJ, Jenkins HA et al. Ionic currents and electromotility in inner ear hair cells from humans. J Neurophysiol 1998; 79: 2235-2239.

9 Holt JR, Corey DP. Ion channel defects in hereditary hearing loss. Neuron 1999; 22: 217-219.

10 Kharkovets T, Hardelin JP, Safieddine S, Schweizer M, ElAmraoui A, Petit $\mathrm{C}$ et al. KCNQ4, a $\mathrm{K}+$ channel mutated in a form of dominant deafness, is expressed in the inner ear and the central auditory pathway. Proc Natl Acad Sci USA 2000; 97: 4333-4338.

11 Nair TS, Kozma KE, Hoefling NL, Kommareddi PK, Ueda Y, Gong TW et al. Identification and characterization of choline transporter-like protein 2, an inner ear glycoprotein of 68 and 72 $\mathrm{kDa}$ that is the target of antibody-induced hearing loss. J Neurosci 2004; 24: 1772-1779.

12 Oghalai JS, Holt JR, Nakagawa T, Jung TM, Coker NJ, Jenkins HA et al. Harvesting human hair cells. Ann Otol Rhinol Laryngol 2000; 109: 9-16.

13 Lin D, Hegarty JL, Fischbein NJ, Jackler RK. The prevalence of "incidental" acoustic neuroma. Arch Otolaryngol Head Neck Surg 2005; 131: 241-244.

14 Howitz MF, Johansen C, Tos M, Charabi S, Olsen JH. Incidence of vestibular schwannoma in Denmark, 1977-1995. Am J Otol 2000; 21: 690-694.

15 Merchant SN, Adams JC, Nadol Jr JB. Pathophysiology of Meniere's syndrome: are symptoms caused by endolymphatic hydrops? Otol Neurotol 2005; 26: 74-81.

16 Semaan MT, Alagramam KN, Megerian CA. The basic science of Meniere's disease and endolymphatic hydrops. Curr Opin Otolaryngol Head Neck Surg 2005; 13: 301-307.

17 Raphael Y, Frisancho JC, Roessler BJ. Adenoviral-mediated gene transfer into guinea pig cochlear cells in vivo. Neurosci Lett 1996; 207: 137-141.

18 Han D, Yu Z, Fan E, Liu C, Liu S, Li Y et al. Morphology of auditory hair cells in guinea pig cochlea after transgene expression. Hear Res 2004; 190: 25-30.

19 Yamasoba T, Yagi M, Roessler BJ, Miller JM, Raphael Y. Inner ear transgene expression after adenoviral vector inoculation in the endolymphatic sac. Hum Gene Ther 1999; 10: 769-774.

20 Stover T, Yagi M, Raphael Y. Cochlear gene transfer: round window versus cochleostomy inoculation. Hear Res 1999; 136: 124-130.

21 Stover T, Yagi M, Raphael Y. Transduction of the contralateral ear after adenovirus-mediated cochlear gene transfer. Gene Therapy 2000; 7: 377-383.

22 Suzuki M, Yamasoba T, Kondo K, Kaga K. Transfection of young guinea pig vestibular cells in vitro with an adenovirus vector. Neuroreport 2001; 12: 4013-4017.

23 Yamasoba T, Suzuki M, Kondo K. Transgene expression in mature guinea pig cochlear cells in vitro. Neurosci Lett 2002; 335: 13-16.

24 Ishimoto S, Kawamoto K, Kanzaki S, Raphael Y. Gene transfer into supporting cells of the organ of Corti. Hear Res 2002; 173: 187-197.
25 Staecker H, Li D, O'Malley BW, Van de Water TR. Gene expression in the mammalian cochlea: a study of multiple vector systems. Acta Otolaryngol 2001; 121: 157-163.

26 Jero J, Mhatre AN, Tseng CJ, Stern RE, Coling DE, Goldstein JA et al. Cochlear gene delivery through an intact round window membrane in mouse. Hum Gene Ther 2001; 12: 539-548.

27 Kawamoto K, Oh SH, Kanzaki S, Brown N, Raphael Y. The functional and structural outcome of inner ear gene transfer via the vestibular and cochlear fluids in mice. Mol Ther 2001; 4: 575-585.

28 Kanzaki S, Ogawa K, Camper SA, Raphael Y. Transgene expression in neonatal mouse inner ear explants mediated by first and advanced generation adenovirus vectors. Hear Res 2002; 169: $112-120$.

29 Dazert S, Battaglia A, Ryan AF. Transfection of neonatal rat cochlear cells in vitro with an adenovirus vector. Int $J$ Dev Neurosci 1997; 15: 595-600.

30 Dazert S, Aletsee C, Brors D, Gravel C, Sendtner M, Ryan A. In vivo adenoviral transduction of the neonatal rat cochlea and middle ear. Hear Res 2001; 151: 30-40.

31 Lalwani AK, Han JJ, Walsh BJ, Zolotukhin S, Muzyczka N, Mhatre AN. Green fluorescent protein as a reporter for gene transfer studies in the cochlea. Hear Res 1997; 114: 139-147.

32 Amalfitano A, Parks RJ. Separating fact from fiction: assessing the potential of modified adenovirus vectors for use in human gene therapy. Curr Gene Ther 2002; 2: 111-133.

33 Amalfitano A. Utilization of adenovirus vectors for multiple gene transfer applications. Methods 2004; 33: 173-178.

34 Kawamoto K, Ishimoto S, Minoda R, Brough DE, Raphael Y. Math1 gene transfer generates new cochlear hair cells in mature guinea pigs in vivo. J Neurosci 2003; 23: 4395-4400.

35 Izumikawa M, Minoda R, Kawamoto K, Abrashkin KA, Swiderski DL, Dolan DF et al. Auditory hair cell replacement and hearing improvement by Atoh1 gene therapy in deaf mammals. Nat Med 2005; 11: 271-276.

36 Boeda B, Weil D, Petit C. A specific promoter of the sensory cells of the inner ear defined by transgenesis. Hum Mol Genet 2001; 10: 1581-1589.

37 Baum SG. Adenovirus.In: Mandell GL, Bennet JE, Dolin R, (eds). Principles and Practice of Infectious Diseases, 6th edn. Elesevier, Inc.: Philadelphia, 2005, pp 1835-1841.

38 Venail F, Wang J, Ruel J, Ballana E, Rebillard G, Eybalin M et al. Coxsackie adenovirus receptor and alphanubeta3/alphanubeta5 integrins in adenovirus gene transfer of rat cochlea. Gene Therapy 2007; 14: 30-37.

39 Derby ML, Sena-Esteves M, Breakefield XO, Corey DP. Gene transfer into the mammalian inner ear using HSV-1 and vaccinia virus vectors. Hear Res 1999; 134: 1-8.

40 Han JJ, Mhatre AN, Wareing M, Pettis R, Gao WQ, Zufferey RN et al. Transgene expression in the guinea pig cochlea mediated by a lentivirus-derived gene transfer vector. Hum Gene Ther 1999; 10: 1867-1873.

41 Stone IM, Lurie DI, Kelley MW, Poulsen DJ. Adeno-associated virus-mediated gene transfer to hair cells and support cells of the murine cochlea. Mol Ther 2005; 11: 843-848.

42 Lalwani AK, Jero J, Mhatre AN. Current issues in cochlear gene transfer. Audiol Neurootol 2002; 7: 146-151.

43 Lalwani AK, Mhatre AN. Cochlear gene therapy. Ear Hear 2003; 24: 342-348.

44 Kros CJ, Marcotti W, van Netten SM, Self TJ, Libby RT, Brown SD et al. Reduced climbing and increased slipping adaptation in cochlear hair cells of mice with Myo7a mutations. Nat Neurosci 2002; 5: 41-47.

45 Kharkovets T, Dedek K, Maier H, Schweizer M, Khimich D, Nouvian $\mathrm{R}$ et al. Mice with altered KCNQ4 K+ channels implicate sensory outer hair cells in human progressive deafness. EMBO J 2006; 25: 642-652. 
46 Staecker H, Praetorius M, Baker K, Brough DE. Vestibular hair cell regeneration and restoration of balance function induced by Math1 gene transfer. Otol Neurotol 2007; 28: 223-231.

47 Johns DC, Marx R, Mains RE, O'Rourke B, Marban E. Inducible genetic suppression of neuronal excitability. J Neurosci 1999; 19: 1691-1697.

48 Amalfitano A, Hauser MA, Hu H, Serra D, Begy CR, Chamberlain JS. Production and characterization of improved adenovirus vectors with the E1, E2b, and E3 genes deleted. I Virol 1998; 72: 926-933.

49 He TC, Zhou S, da Costa LT, Yu J, Kinzler KW, Vogelstein B. A simplified system for generating recombinant adenoviruses. Proc Natl Acad Sci USA 1998; 95: 2509-2514.

50 Hodges BL, Serra D, Hu H, Begy CA, Chamberlain JS, Amalfitano A. Multiply deleted [E1, polymerase-, and pTP-] adenovirus vector persists despite deletion of the preterminal protein. J Gene Med 2000; 2: 250-259.

Supplementary information accompanies the paper on Gene Therapy Web site (http://www.nature.com/gt) 